\title{
Building Mathematical Models for Multicriteria and Multiobjective Applications 2017
}

\author{
Adiel Teixeira de Almeida ${ }^{D},{ }^{1}$ Love Ekenberg $\mathbb{D}^{2},{ }^{2,3}$ Juan Carlos Leyva Lopez ${ }^{D},{ }^{4}$ \\ and Danielle Costa Morais ${ }^{1}{ }^{1}$ \\ ${ }^{1}$ Department of Management Engineering, Universidade Federal de Pernambuco, Recife, PE, Brazil \\ ${ }^{2}$ International Institute for Applied Systems Analysis (IIASA), Schlossplatz 1, 2361 Laxenburg, Austria \\ ${ }^{3}$ Department of Computer and Systems Sciences, Stockholm University, Stockholm, Sweden \\ ${ }^{4}$ Department of Economic and Management Sciences, Universidad Autónoma de Occidente, Culiacán, SIN, Mexico
}

Correspondence should be addressed to Adiel Teixeira de Almeida; almeida@cdsid.org.br

Received 1 March 2018; Accepted 4 March 2018; Published 22 April 2018

Copyright (C) 2018 Adiel Teixeira de Almeida et al. This is an open access article distributed under the Creative Commons Attribution License, which permits unrestricted use, distribution, and reproduction in any medium, provided the original work is properly cited.

This special issue has been requested by developers of the publisher based on the success of "Building Mathematical Models for Multicriteria and Multiobjective Applications 2016." As a result, this special issue is one of the publisher's Annual Special Issues. That is, it is the first issue in a series of special issues which will be published each year. It is hoped that such a series will attract the MCDM/A community and have a long-term impact on researchers and practitioners alike, particularly on those interested in building mathematical decision models for applications in real or realistic situations.

Therefore, this special issue addresses decision problems involving multiple criteria, which may be conflicting and explicitly incommensurable. Multicriteria decisionmaking/aid (MCDM/A) and multiobjective methods can be highly useful for decision-makers (DMs) in such tasks. A large number of high-quality papers were submitted for consideration in this special issue. After a rigorous peerreview process, thirteen papers were accepted (an acceptance rate of around $20 \%$ ). They cover and discuss a variety of applications for real-world problems, while combining theoretical methodology and mathematical analysis. The authors of these papers are active in different countries around the world, namely, Brazil, Mexico, Canada, China, India, Pakistan, and Spain.

In the field of supplier selection, four papers are presented that deal with different methodologies and problems in that context. Q. Pang et al. propose a method that integrates fuzzy set theory and grey relational analysis (a fuzzy-grey approach) in order to select a green supplier in a low-carbon supply chain. Based on the demand of companies in a lowcarbon supply chain, 4 main criteria and 22 subcriteria are established for selecting a green supplier.

R. Krishankumar, S. Ravichandran, and R. Ramprakash present a computational framework for cloud vendor selection by proposing IVIF-ELECTRE (IVIFE), an interval valued intuitionistic fuzzy (IVIF) environment based on ELECTRE method. This proposal was formulated and integrated with the popular TOPSIS method so as to obtain a linear ranking. The practicality of the proposed framework is demonstrated by using a supplier selection example while its strength is made apparent by comparing it with other similar methods.

E. A. Frej et al. developed a decision model for solving a supplier selection problem in a food industry by conducting preference modeling using a flexible and interactive elicitation technique with the decision-maker (DM), aided by the FITradeoff method. FITradeoff DSS also provides graphical visualization for the DM at each step in a flexible way, so that the DM can holistically analyze the performance of the potentially optimal alternatives.

X. Sun puts forward a max-max model to facilitate selecting the optimal combination of suppliers. The paper presents an analytical model that describes the synergies 
between components of a product and supplier selection criteria that enhance the effectiveness of supplier selection.

To enhance air traffic control, F. Tello et al. present a multiobjective perspective on a scheduling problem regarding the work-shifts of air traffic controllers (ATC). This approach, given a fixed number of ATCs and an airspace sector to cover, optimizes several objectives. These are to do with ATC duties, rest periods, and positions; the structure of the solution; the number of control center changes, or the distribution of ATC workloads, while satisfying a set of ATC working conditions set out in Spanish regulation.

Still using the multiobjective perspective, Y. Yang et al. propose a new multiobjective optimization design method, which combines a support vector regression (SVR) surrogate model and a nondominated sorting genetic algorithm (NSGA-II), in order to undertake the multiobjective optimization of the location and layout of fixtures of sheet metal parts (SMP) and to reduce the excessive cost of computing fine element analysis (FEA) during the iterative optimization. The authors illustrate the proposed method by locating and fixing the layout of the skin of an aircraft fuselage.

As to the problem of planning the response to and recovery from a disaster, L. B. Cavalcanti, A. B. Mendes, and H. T. Y. Yoshizaki propose a method of how to improve planning for delivering cargo in the aftermath of a disaster by using value-focused thinking (VFT) and the SMARTER method. VFT was applied to elucidate the objectives of delivering cargo to disaster victims during response operations and to create solution alternatives. SMARTER method was applied to evaluate the alternatives; in this case, strategies for planning the delivery of aid to disaster victims.

For the problem of product selection, S. Latif et al. introduce the optimum selection of the next forwarder vehicle (NFV) which is used to disseminate data in a vehicular ad hoc network (VANET) using the analytical network process (ANP). The NFV is selected on the basis of three parameters, namely, direction, position and distance. This paper also presents a mathematical model to compute the priorities of vehicles within a network.

As to the construction sector, C. C. G. Famá and L. A. Alencar put forward a model for classifying managers by competencies, using the NeXClass method in order to match each manager to the position that is the most appropriate for them based on assessing their competencies and performance on construction projects to date. This model can be useful not only for those responsible for selecting managers but also for the employee who aspires to be a manager.

H. Liang, S. Zhang, and Y. Su develop a composite index to measure the multidimensional concept of industrialization efficiency in prefabricated residential buildings, by applying the fuzzy analytic hierarchy process (fuzzy AHP) and the fuzzy technique for order preference by similarity to ideal solution (fuzzy TOPSIS), thereby combining the hierarchical structures of indicators into one overall index.

X.-Z. Zheng, F. Wang, and J.-L. Zhou develop the human factors analysis and classification system (HFACS) framework to deal with a hydropower project construction for evaluating faulty behavior risk (FBR) of high-risk operations using ANP and evidence theory.
Dealing with joint methodologies, A. Frini proposes multicriteria intelligence aid (MCIA) which extends multicriteria decision aid (MCDA) to the context of analyzing intelligence. The MCIA steps consist of (i) structuring the competitor/threat decision problem, (ii) handling imperfect data, (iii) modeling the analyst's attitude towards risk, and (iv) aggregating the performance of the potential actions generated. An example of its application is provided based on a military context.

N. Rangel-Valdez et al. set out and discuss the robustness of a preference-disaggregation analysis (PDA) metaheuristic method to estimate the parameters for a model of an outranking-based relational system of preferences. This proposal presents a method for analyzing the robustness of PDA strategies that work with the complete set of the parameters of the ELECTRE III model. The method is considered robust if the solutions obtained in the presence of noise can maintain the same performance in predicting preference judgments in a new reference set. The research shows experimental evidence that the PDA method keeps the same performance in situations with up to $10 \%$ of noise level, thus making it robust.

Despite the significant spread of MCDM/A methods, the variety of applications discussed in this special issue can only cover a small diversity of contexts in which they might be applied. The papers demonstrate the extensive range of contexts over which these methods can be used and we hope that they will prompt and encourage readers to contribute towards further developments in building MCDM/A models in the future.

\section{Acknowledgments}

We would like to express our deepest gratitude to the authors for their contributions to this special issue and the cooperation and assistance of many reviewers, whose feedback was very useful in improving the quality of papers submitted. Also, we record our genuine gratitude to other editors of the editorial board for their cooperation by coordinating the editorial process for those contributions in which one of the Editors of this special issue was a co-author.

Adiel Teixeira de Almeida Love Ekenberg Juan Carlos Leyva Lopez Danielle Costa Morais 


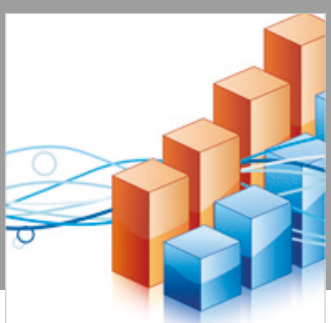

Advances in

Operations Research

\section{-n-m}
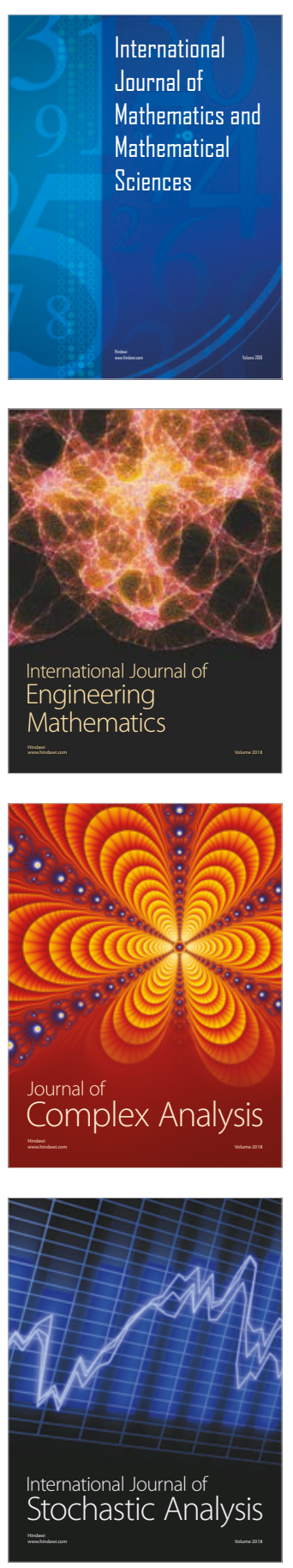
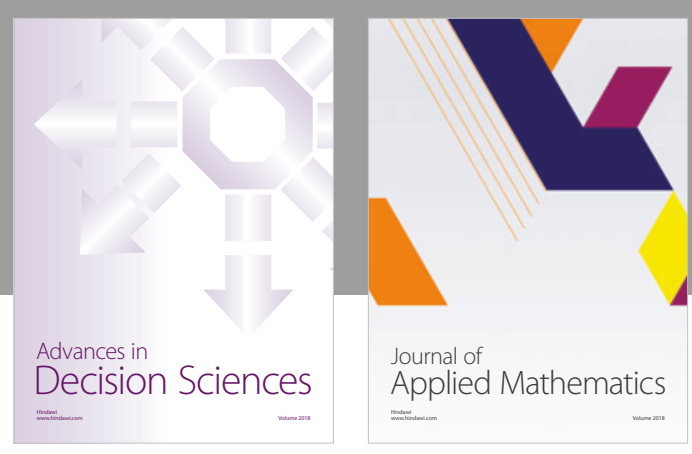

Journal of

Applied Mathematics
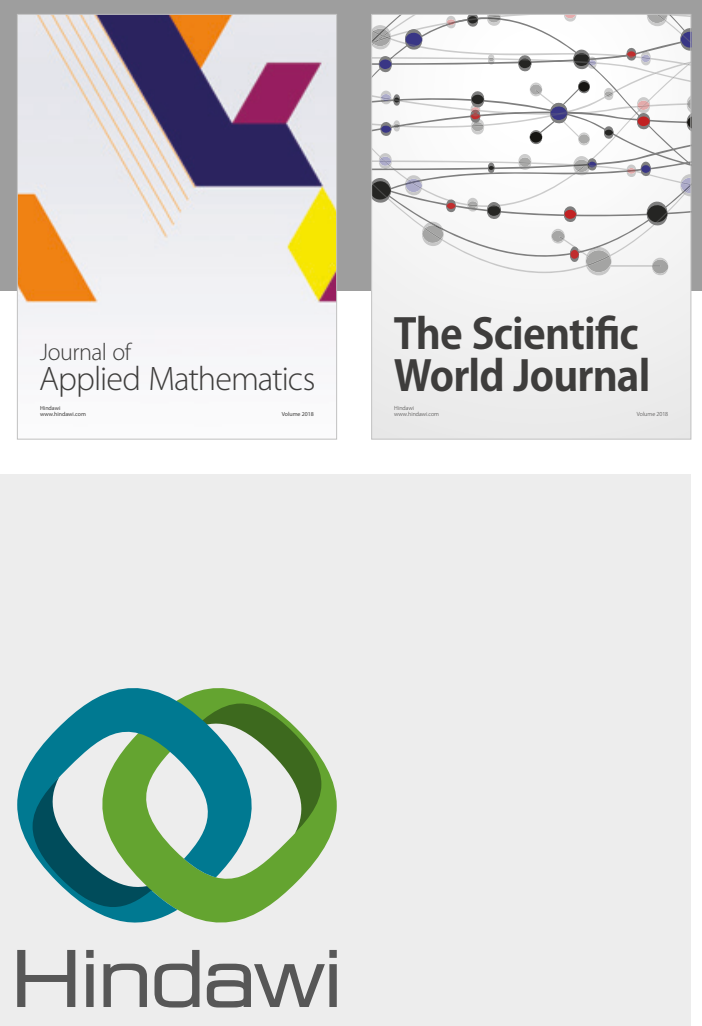

Submit your manuscripts at

www.hindawi.com

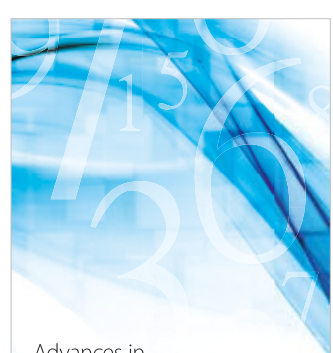

Advances in
Numerical Analysis
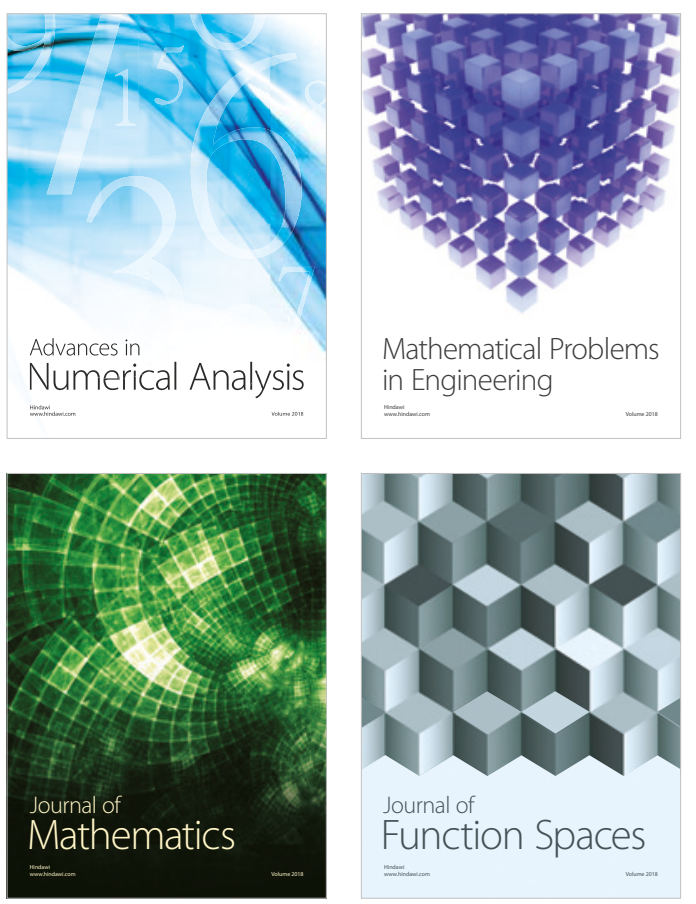

Mathematical Problems in Engineering

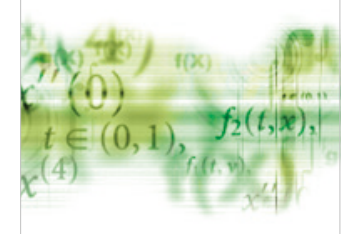

International Journal of

Differential Equations

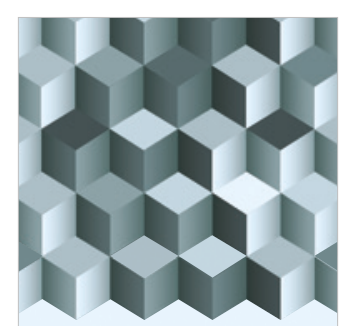

Journal of

Function Spaces

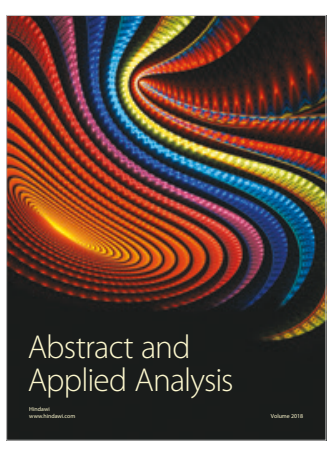

The Scientific

World Journal

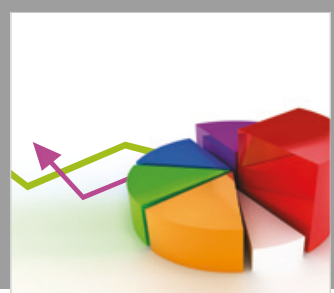

Journal of

Probability and Statistics
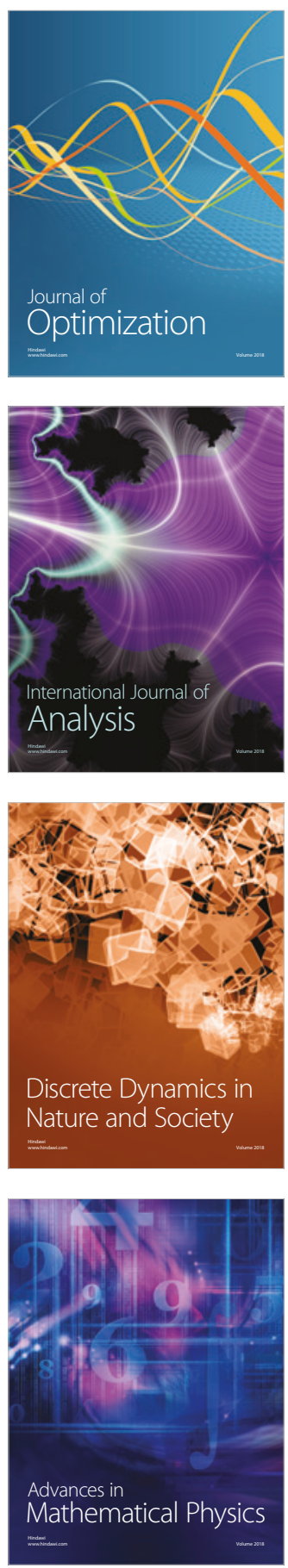